\title{
"Am I my genes?": Questions of identity among individuals confronting genetic disease
}

\author{
Robert Klitzman, MD
}

\begin{abstract}
Purpose: To explore many questions raised by genetics concerning personal identities that have not been fully investigated. Methods: We interviewed in depth, for 2 hours each, 64 individuals who had or were at risk for Huntington disease, breast cancer, or alpha-1 antitrypsin deficiency. Results: These individuals struggled with several difficult issues of identity. They drew on a range of genotypes and phenotypes (e.g., family history alone; mutations, but no symptoms; or symptoms). They often felt that their predicament did not fit preexisting categories well (e.g., "sick," "healthy," "disabled," "predisposed"), due in part to uncertainties involved (e.g., unclear prognoses, since mutations may not produce symptoms). Hence, individuals varied in how much genetics affected their identity, in what ways, and how negatively. Factors emerged related to disease, family history, and other sources of identity. These identities may, in turn, shape disclosure, coping, and other health decisions. Conclusions: Individuals struggle to construct a genetic identity. They view genetic information in highly subjective ways, varying widely in what aspects of genetic information they focus on and how. These data have important implications for education of providers (to assist patients with these issues), patients, and family members; and for research, to understand these issues more fully. Genet Med 2009:11(12): 880-889.
\end{abstract}

Key Words: genetic testing, risk, illness experiences, doctor-patient communication, stigma

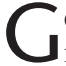
enetics have many profound implications for personal identity that have not been fully investigated. Genetics are deeply constitutive of the self, but the field is still relatively new, with many new markers discovered and marketed each year, and physician and patient understandings of genetics often remain limited. ${ }^{1}$

Other kinds of disease can powerfully shape individuals' identities, ${ }^{2,3}$ but genetics may pose particular challenges. Sex, social class, and particular aspects of a disease can affect how patients integrate into their lives chronic diseases such as multiple sclerosis and cancer, ${ }^{4}$ renegotiating identity, and constructing their biographies. ${ }^{5}$ Perceptions of stigma due to illness can profoundly affect individuals' perceptions of themselves. ${ }^{3}$ Illness identity, particularly with chronic disease, has been found to be related to coping, and views of, and adherence to, medication, ${ }^{6-8}$ attendance at follow-up appointments, and return to work. ${ }^{9}$ Treatment can affect self-views as well. Radical surgery,

From the Department of Psychiatry, College of Physicians and Surgeons and Mailman School of Public Health, Columbia University, New York, New York.

Robert Klitzman, MD, Department of Psychiatry, College of Physicians and Surgeons and Mailman School of Public Health, Columbia University, New York, NY 10032. E-mail: rlk@columbia.edu.

Disclosure: The author declares no conflict of interest.

Submitted for publication July 8, 2009.

Accepted for publication September 3, 2009

DOI: $10.1097 /$ GIM.0b013e3181bfd212 for example, can affect both private selves and public social identities. ${ }^{10}$

For a few genetic disorders, several aspects of identity have been explored, but many questions remain. Research has been divided on whether genetic risk information harms "self-concept." 11 Scales have purported to assess self-concept and illness identity (e.g., operationalized as symptoms that patients identify as part of their illness). ${ }^{7}$ But this disagreement in findings suggests broader questions of what exactly constitutes "selfconcept," how learning one's genetic risk can affect one's identity, what challenges individuals then face, and how they deal with these. For example, research has found that individuals who are carriers, noncarriers, and at risk for a disease may all experience threatened self-concept (e.g., in terms of personal, physical, genetic, social, and family identity), ${ }^{11}$ but it remains unclear in what ways and how.

The Oxford English Dictionary defines "identity," from the Latin "idem" for "same," as "the condition or fact of a person or thing being that specified unique person or thing . . . a continuous, unchanging property throughout existence; the characteristics determining this ..." The word "self," from old English and old German, is defined as the "particular person(s) . . or things(s) ... in question." Thus, "identity" arises from Latin, whereas "self" arises from German. ${ }^{12}$

A variety of social scientists have used these terms focusing on different aspects of these. For instance, a range of psychologists have probed identity development. Erikson ${ }^{13}$ focused on the stages in the development of identity through the life cycle-from childhood to adolescence to adulthood. He argued that individuals make commitments in three main domainsfidelity, ideology, and work - that shape their identity development. Psychologists have examined other aspects of identity development as well-e.g., proposing stages of moral ${ }^{14}$ and cognitive development. ${ }^{15}$ However, clearly, adults learn of their genetic risks only in the last of later life cycle stages. Sociologists, too, have explored identity - at the level of broad social groups, categories, and roles (e.g., identity as a member of a minority group or of a particular profession), and of the individual person, and have often emphasized the social forces that shape identity formation. ${ }^{16,17}$ More recently, postmodern theorists have argued that concepts of selfhood are "constructed," either individually or socially, rather than biologically based. ${ }^{18}$ Controversies have emerged, too, as to whether an individual consists of multiple selves, rather than a single self. ${ }^{19}$

With regard to genetics, Zeiler proposed a multilayered concept of identity that can include genetic, personal, gender, or narrative identities. She described several conceptions of identity_qualitative, numerical (i.e., being one person or two), genetic, and exact or approximate genomic (reflecting DNA in both the nucleus and the mitochondria). She distinguished, too, between "identity-over-possible-worlds," "identity as certain properties of the person" (e.g., sex, ethnicity, or personality), or "identity-over-time"; and between "functional and sequential genomic identity." 20 More recently, Zeiler ${ }^{21}$ has argued as well that "the way genetics is used . . . highlights the need to explore its effect on selfhood, on issues of identity and behavior." 
"Personalized genomics" has raised concerns that it may create stratified groups and promote "individualistic" as opposed to "communitarian" (or other) notions of selfhood, each of which, alone, may be inadequate. ${ }^{22}$ However, genetic testing companies' on-line advertisements have been found to use rhetoric of "personalized" genetic profiles to emphasize links between genetics and identity. ${ }^{23}$

Individuals view genetic risks in subjective ways, ${ }^{24}$ but it remains unclear how they actually approach issues of identity - how they incorporate these risks into their sense of themselves and their identities. Although "identity" has been mentioned as a possible factor in previous discussions of genetic risk assessments, ${ }^{1,25}$ it has received little focused attention in these discussions. Many questions persist concerning its nature and scope-e.g., how it may interact with other phenomena, how exactly individuals decide whether, how, and to what degree genetic risks affect their identity, and what processes and factors are involved. Shiloh ${ }^{25}$ suggested self-regulatory theory as a framework for conceptualizing genetic counseling, whereby clients actively process information; and identity (i.e., impression of and experience with the illness) is one of 14 sets of factors involved in genetic counseling. However, questions arise of what factors shape the "identity" that an individual has, and how and why. Similarly, Walter and Emery ${ }^{1}$ provide a model of familial risk perception in which individuals assess the salience of a new affected relative for themselves, undergoing a "personalizing process" through which they develop a "personal sense of vulnerability" that affects coping and control and that can in turn further affect the salience. But here, too, questions emerge of how individuals incorporate this personal sense of vulnerability into their identity and sense of themselves - e.g., how their notions of "vulnerability" affect how they see themselves. Armstrong et al. ${ }^{26}$ suggest that while developing a chronic disease involves a readjustment in one's previous self-concept and a negotiation between new and old identities, genetic disease entails not a "new identity," but "revealing" an underlying one (i.e., one's genetic risk) that was in fact, always present, if unknown. However, a genetic disease may already have caused symptoms, and thus involve a "new identity" as well.

Of note, attention has also been given to issues of how genetic markers may affect social-specifically, racial and ethnic-identities. For instance, several so-called "ancestry" genes have been identified, and relationships have been probed between genetic versus public (or individual versus social) identities. ${ }^{27}$ But, the precise biological or other meanings of these "ancestry" genes remain unclear. An individual can have multiple such markers, and these genetic data may not coincide with one's personal views of one's identity. ${ }^{28}$ Because genetic markers have been identified for diseases far more than for ancestry, genetic identities related to disease can potentially shed light on how individuals integrate genetic data into their views of themselves more broadly as well. Hence, this article focuses on markers related to disease, not ancestry per se.

In short, given these varied perspectives on identity in the previous literature, critical questions remain of how individuals who are at risk for, or have, genetic diseases themselves view and experience these issues, and incorporate genetic risk information into their identities and senses of themselves-e.g., how they themselves, in fact, approach issues of identity, what challenges they face, and whether and how these identities might affect health decisions.

\section{METHODS}

As shown in Table 1, we interviewed, for 2 hours each, 64 individuals, who had or were at risk for one of three disordersHuntington disease (HD), breast cancer (BC), and alpha-1 antitrypsin deficiency (alpha). We selected a heterogenous group to understand most fully the ranges of issues and perspectives that could arise regarding genetic issues.

To recruit participants, we distributed information about the study through clinics, studies at our institution, newsletters, flyers displayed on bulletin boards of our institution, and word of mouth. Individuals contacted the principal investigator (PI) if they were interested. With each participant, the PI conducted a confidential in-depth semistructured interview concerning experiences of having, or being at risk for $\mathrm{BC}, \mathrm{HD}$, or alpha. Interviews were conducted in the PI's office and took approximately 2 hours, although varying somewhat in length. Our institutional review board approved the study, and all participants gave informed consent. We sought to obtain detailed descriptions of the process of individuals' views and decisions concerning genetic testing.

On theoretical grounds, Geertz ${ }^{29}$ has advocated studying aspects of individuals' lives and social situations not by imposing external theoretical structures but by trying to understand individuals' own experiences, drawing on their own words and perspectives to obtain a "thick description." Hence, to understand most fully the range of factors and issues that may be involved in genetic testing decisions, we used qualitative methods.

Table 1 Characteristics of samples

\begin{tabular}{lrrrr}
\hline & \multicolumn{3}{c}{ Disease } & \\
\cline { 2 - 4 } & $\mathrm{BrCa}$ & HD & Alpha & Tota \\
\hline Gender & 32 & 9 & 7 & 48 \\
Female & 0 & 12 & 4 & 16 \\
Male & & & & \\
Ethnicity & 21 & 18 & 11 & 49 \\
White & 7 & 2 & 0 & 6 \\
Black & 1 & 0 & 0 & 1 \\
Asian & 1 & 1 & 0 & 4 \\
Hispanic & 2 & 0 & 0 & 3 \\
Others & & &
\end{tabular}

Symptom status

Symptomatic

20

7

11

Asymptomatic

12

14

0

Test status

\begin{tabular}{lrrrr} 
Positive & 8 & 10 & 11 & 29 \\
Negative & 8 & 4 & 0 & 12 \\
Indeterminate & 3 & 0 & 0 & 3 \\
Not tested & 13 & 7 & 0 & 20 \\
Total & 32 & 21 & 11 & 64 \\
\hline BrCa, breast cancer; HD, Huntington disease; Alpha, alpha-1 antitrypsin deficiency
\end{tabular}




\section{Data analysis}

We have adapted elements from grounded theory, as described by Strauss and Corbin, ${ }^{30}$ because we were interested in understanding a complex social process. We have used these methods in several other studies involving genetics. ${ }^{31}$ Specifically, grounded theory involves both deductive and inductive thinking, building inductively from the data to an understanding of themes and patterns within the data, and deductively drawing on frameworks from previous research and theories. Our approach was informed constant comparison in which data from different individuals were compared for similarities and differences to see whether these suggested hypotheses. Transcriptions and initial analyses of interviews were performed during the period in which the interviews were being conducted and helped guide subsequent interviews. Interviews were conducted until saturation was reached.

Once the full set of interviews was completed, subsequent analyses were conducted in two phases, primarily by the PI together with a research assistant (RA) who had social science training. In phase I of the coding, the PI and the RA independently examined a subset of interviews to assess factors that shaped participants' experiences, identifying categories of recurrent themes, and issues that were subsequently given codes. These two coders assessed similarities and differences among participants, examining themes and categories that emerged, ranges of variation within categories, and variables that may be involved. The coders systematically coded blocks of test to assign "core" codes or categories. While reading the interviews, a topic name (code) was inserted beside each excerpt of the interview to indicate the themes being discussed. The coders then worked together to reconcile their independently developed coding schemes into a single scheme, developing a coding manual and examining areas of disagreement until reaching consensus between them. New themes that did not fit into the original coding framework were discussed, and modifications were made in the manual when deemed appropriate.

In the next phase of the analysis, we subdivided thematic categories into secondary or subcodes, and then refined and merged these, when suggested by associations or overlap in the data. Codes and subcodes were then used in analysis of all of the interviews. Major codes (or categories) of text included, for example, responses to genetic test results, and views of self and of others with and without a mutation. Subcodes (or subthemes) were conceptual and thematic subdivisions of these larger categories and included, for example, views of self as "disabled," "diseased," or "mutant." To ensure coding reliability, these two coders analyzed all interviews. We examined areas of disagreement until consensus was reached. To ensure trustworthiness, we triangulated the data with existing literature relating to genetic discrimination. These data also have a certain face validity that, we would suggest, further substantiates their trustworthiness. We have presented the below text from the interviews to allow readers to judge these data for themselves as well. We have indicated whether interviewees are symptomatic (Sx) or asymptomatic (Asx), and mutation positive (+), negative $(-)$, inconclusive, or untested (Unt).

\section{RESULTS}

\section{Challenges in incorporating genetic status into one's sense of self}

Overall, as outlined in Figure 1, individuals wrestled with a series of challenges concerning identity. Given the fact that genes "make us," individuals faced questions of how, to what degree, and with what implications. In varying ways, they sought to incorporate the fact of being at risk into their lives and senses of self. They often viewed these issues highly subjectively, differing in what aspects of the "condition" they focused on, and how and to what degree they did so. Several factors shaped these choices.

In constructing an identity, individuals drew on a spectrum of genetic categories - of genotypes and phenotypes - but interpreted these aspects of their respective conditions, and types of objective data in a wide range of ways. Individuals were tested or untested; and if tested, they were mutation positive or negative (or, rarely, had indeterminate results). These individuals differed in phenotypes - i.e., in whether they had symptoms or not. If they had symptoms, these ranged from possibly to definitively related to the disease; and from mild to fatal. These genotypes and phenotypes in turn combined varyingly across a spectrum, from having only a family history of disease, but no symptoms or testing; to having a mutation, but being asymptomatic; to having possible symptoms, but being untested; to having possible symptoms and being mutation positive; to having definitive symptoms. However, across this range, similar sets of questions emerged as individuals interpreted each of these respective states. At one end of the spectrum, merely a family history of a disease without any symptoms could affect one's identity, shadowing one.

I think of myself now as "someone at risk." That's how most people in my family die. That means, unscientifically, that it's "in my family," so I should pay attention to it. $(B C 2-A s x /-)$

Even, in the absence of genetic testing, risk alone can thus shift an individual's identity.

\section{Approaching preexisting, socially established categories}

Genetic categories of genotypes and phenotypes involved ambiguities that individuals had to try to grasp and weigh, usually by looking to other socially established categories. Specifically, individuals wrestled with questions of whether they were "predisposed," "sick," "diseased," "healthy," or "disabled," and if so, how (i.e., what these various categories meant). These individuals thus sought to understand their genotypes and phenotypes in varying ways; but often felt that these existing disease-related social categories were inadequate or problematic. Many with alpha, e.g., wondered if they even had a "disease," and felt instead that they had a "condition." However, they then struggled to distinguish between these two terms. They suggested, too, the roles of social inputs in making determinations. Support groups encouraged them to avoid the label "disease," because it may carry negative connotations, but the reasons for this distinction were not always wholly clear to these individuals.

I don't always think of alpha as a "disease", as much as I do a "condition." Maybe I'm wrong. I don't know what the definition is, but I always think of "disease" as something you contract, not are born with. It's the seriousness of what it is. Diseases can be self inflicted. $(A 9-S x /+)$

In contrast, another man with alpha struggled to distinguish between these terms, and did so differently, saying,

The disease is emphysema, but the condition is Alpha- 1 . $(A 4-S x /+)$ 


\begin{tabular}{|c|c|c|c|}
\hline $\begin{array}{l}\frac{\text { Challenges in incorporating }}{\text { genetic status into one's }} \\
\text { sense of self } \\
\text { - Genes "make us" } \\
\text { 口 but how, to } \\
\text { what degree and with what } \\
\text { implications? } \\
\text { - Individuals vary in } \\
\text { incorporating genetic risk } \\
\text { and/or disease into identity/ } \\
\text { sense of self } \\
\text { - Difficulties and differences in } \\
\text { constructing a "genetic self" }\end{array}$ & 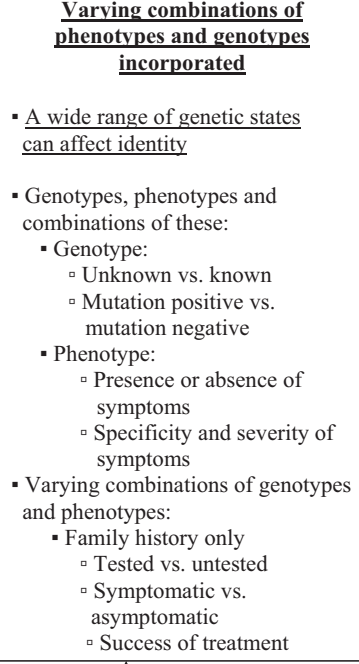 & \multirow[t]{2}{*}{$\begin{array}{l}\text { Problems in integration } \\
\text { - Multiple ambiguities involved } \\
\text { - } \text { Prognoses uncertain } \\
\text { - States and their identities can } \\
\text { change over time } \\
\text { - Disease treated, but can recur } \\
\text { - Wide range of pre-existing disease- } \\
\text { related categories: } \\
\text { - "being at risk"? } \\
\text { - Predisposition vs. disease? } \\
\text { - Disease vs. condition? } \\
\text { - Healthy vs. sick? } \\
\text { - Normal vs. abnormal? } \\
\text { - Disabled vs. able? } \\
\text { - Survivor? } \\
\text { - Searching for intermediate states } \\
\text { - Applying several categories to } \\
\text { oneself } \\
\text { - Diagnosis as part vs. whole of self } \\
\text { - Not important } \\
\text { - Small part of self } \\
\text { - Large part of self } \\
\text { - Moral aspects of categories } \\
\text { - Negativity vs. neutrality of } \\
\text { condition } \\
\text { - "mutant" vs. not }\end{array}$} & \multirow[t]{2}{*}{ 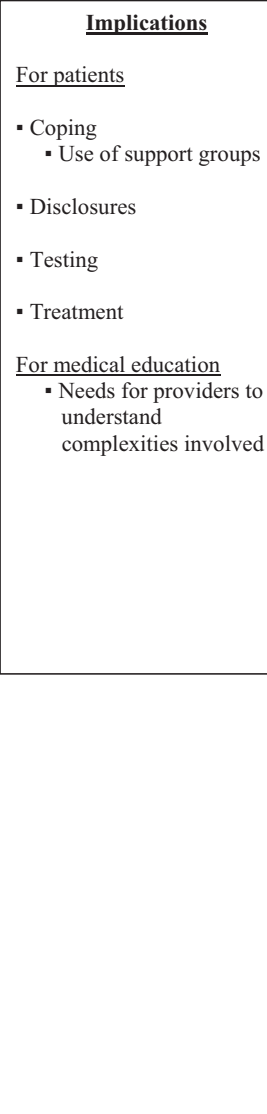 } \\
\hline $\begin{array}{r}\text { - Patient's medical his } \\
\text { - Extent of dis } \\
\text { - Treatment re } \\
\text { - Family medical histo } \\
\text { - Psychological } \\
\text { - Other sources of idel } \\
\text { - Balancing g } \\
\text { - Prior person } \\
\text { - Prior trauma } \\
\text { - Perceived st } \\
\text { - Scientific ed } \\
\text { - Social conte } \\
\square \text { Sup }\end{array}$ & $\begin{array}{l}\text { rs Involved } \\
\text { other aspects of self } \\
\text { nces and views of self } \\
\text { opposing patient }\end{array}$ & & \\
\hline
\end{tabular}

Fig. 1. Themes concerning genes and identity.

Others felt they had a "predisposition," which they then sought to distinguish from having a "disease." But the former "state" can itself also be ambiguous, having physiological, clinical, and/or pathologic implications. Some challenged the term "predisposition" because they felt it did not represent a full prediction, since they felt they could potentially influence their fate- e.g., by adopting or avoiding certain behaviors.

I have a predisposition to a couple of diseases. I'm low in a certain protein. But I'm not going to suddenly get sick. If I hadn't smoked, I don't think I'd ever get sick. If I create risky behavior, I'm more likely to succumb to that disease. The risky behavior was smoking. Drinking might be risky because of liver disease. Other risky behaviors might be working in a chemical factory, or with perfumes. I know people working in dental offices with strong odors that may be carcinogenic, and in coal mines. A lot of farmers have problems because of dust when they plow. Risky behavior doesn't necessarily mean "bad" behavior. It just puts you at risk for lung or liver disease. I wish I wouldn't have smoked. $(A 10-S x /+)$

He thus wrestles with the meanings of "predisposition," seeking to maintain a sense that he has a modicum of control over his fate, since he might otherwise feel fatalism and despair. Moral issues arise, too, as he seeks to distinguish between risk factors such as smoking, which he sees as self-inflicted (and hence blameworthy) versus occupational exposures for alpha (in which the patient is implicitly "innocent"). In so doing, he seeks to distinguish between two different definitions of "bad"- as morally wrong or physically harmful. He sees himself as having predispositions, but ultimate control as well. He also seeks innocence, wishing he had not smoked because of both the health reasons, and the implicit culpability (i.e., that he had therefore contributed to his own disease).

Individuals differed, too, in the degrees to which they saw themselves as fitting the categories "sick" versus "healthy." For example, despite having had $\mathrm{BC}$, some with $B R C A$ 1/2 mutation still saw themselves as "healthy."

I don't feel I'm a "sick person." I feel I'm very healthy. I know women who say, "I have cancer." I never thought like that. I don't look at myself as being sick. I go for my check-ups, but it definitely doesn't affect my everyday life. $(B C 9-S x /+)$

She adopts implicitly functional definitions of "sick" versus "healthy," based not on whether she had a disease, but on whether she feels her state affects her daily life, and hence her sense of who she is.

The temporal and medical instability and precariousness of "being at risk" leads, too, to searches for alternative terms and categories. Characteristics of specific diseases can help shape these categories. Thus, those with alpha may think of themselves as occupying intermediary positions on a spectrum between sick and healthy - underscoring how alpha can be more 
of a chronic disease than, e.g., BC. For example, one woman with alpha thought of herself as both "sick" and "better," but still "vulnerable."

I think of myself as sick: I'm better for now, but could crash tomorrow-like when we made a 10-hour dash to the hospital. If I have organ rejection, and we can't get it to stop, you're gone. $(A 3-S x /+)$

She acknowledges the precarious and ephemeral nature of these states, focusing only on the present moment. Here, too, she switches from the first to the more general second person, distancing herself slightly from the full threat.

Related questions arise of whether and when a mutation is "normal" versus "abnormal," with all the implied possible moral and other implications of each term. For so-called "complex" genetic disorders (e.g., hypertension or depression), genetic predispositions may, in fact, be "normal variants" of genes. Thus, genetic variations that contribute to diseases can be more "normal" than "abnormal." At times, individuals pursued and used new phrases to try to grasp these complex and diverse states. For instance, one woman described herself as "a healthy alpha."

I think of myself as healthy for my age and disability. That doesn't make a whole lot of sense, but that's how I think of it. I'm a healthy alpha. We have a disease, but not a lot of alphas really present symptoms. So, symptoms don't necessarily define illness. $(A 6-S x /+)$

She still views herself as part of the alpha disease community, but as "healthy," suggesting how these identities are not simply binary, but nuanced across gradients, with individuals at times seeking to straddle several categories that may seem, from afar, to be conceptually distinct.

Still, integrating the diverse characteristics involved in these predicaments pose difficult psychological challenges. Some think of themselves as healthy for the present, but threatened by a bad fate hanging over their heads - reflecting the persistence of uncertainty over time.

Sometimes I think of myself as healthy, but doomed. I don't think of myself as sick, or as a mutant, but as healthy, but on the edge, healthy, but with a curse. This gene is like a curse hanging over me. There is a high risk of another cancer. It's unpleasant. It doesn't enter into everything I do-all of my functioning or everyday life- but just sort of hangs there. There's probably about a $65 \%$ chance I'll get it in my other breast. Then, I read studies that say: $50 \%$. $(B C 8-S x /+)$

The fact that researchers dispute the exact probabilities exacerbates her sense of uncertainty. She struggles to find a degree of surety, seeking scientific data, but seeing the uncertainty metaphysically - that she is "cursed," though she is not entirely clear by whom, or how.

Certain individuals saw themselves as "disabled," more than diseased, suggesting how functioning (what one does, or can do) also shapes identity. The fact that a disease is genetic can shape identity is less important than the fact that the disease causes particular functional disabilities.

"Disabled" is a good way of looking at it: I can't do everything. Some days, even when I'm medicated for depression, I'm just not going to feel up to doing anything. I've come to realize that. $(H D 6-S x /+)$
However, the meanings of "disability" vary, too. To some, it is merely a financial, not a psychological state-an economic situation (i.e., receiving disability benefits), not an identity. One man with alpha, who does not now work, thought of it as merely bureaucratic, more than reality-based.

I don't think of myself as "disabled"- that's a whole political game. I think I could still now do the job I did, but I don't know that I have the mindset. $(A 10-S x /+)$

How much an individual fits this category of disability can also fluctuate over time- even daily, depending on how one defines the term. Not surprisingly, many individuals then struggle with how to define the word, and how and when to apply it to themselves-how to assess whether it describes them, and what factors are involved.

I now think of myself as borderline: I can pass for not being disabled. But I do get tired and irritable, and a lot of times just don't want to do things. People say, "Oh, let's do something on the 26th. Are you free?" Well, maybe/maybe not. I get a lot of infections. I am less disabled than before, because I am now getting the right dose of medicine. My health has improved. I'm thinking of getting a job. But it is hard to do things. If I meet a new person, I'm cautious in telling. $(A 1-S x /+)$

Disease fluctuations over time can thus complicate states of identity. She suggests that degrees of disability can be difficult to predict, and she is concerned that other individuals may or may not agree with her own assessment, which can raise additional stresses. These questions about identity can hence also prompt dilemmas about whether to disclose one's conditions to others, and if so, who, what, how, and when.

A successfully "treated" disease that can recur poses additional questions of identity. With BC, e.g., individuals may see themselves as "survivors" if they have been asymptomatic for several years. But they may still face stressful uncertainties. Even if their entire tumor is removed, cancer can still reappear. After no longer being acutely ill, questions of identity then linger: e.g., how much to stay involved in a disease community and/or to consider oneself to be a patient in some way. Many individuals feel uncomfortable with the term "cancer survivor," since they feel it is an inherently unstable state, although the popular media and many patient advocacy groups commonly invoke it. As one woman said,

I don't look at myself as a BC survivor: "I'm a survivor, let me proudly wear my hat and pin." There's nothing wrong with that. But I don't. I do hotline work. I don't do the Walk-a-thon, but do cancer runs - for cancer research in general, not just BC. I don't look at myself as "genepositive person." I always say "I'm a $\mathrm{BrCa}-1$ carrier." I would say I'm outgoing, athletic, enjoy people, and am sensitive. But I don't describe myself as a "cancer survivor." $(B C 4-S x /+)$

She suggests several alternative, competing ways she could describe herself. She prefers the term "carrier" because it suggests less definitive disease, and perhaps less stigma than "cancer survivor" or "gene-positive" person. She also illustrates the multiple activities in which one can engage within the $\mathrm{BC}$ 
community, all of which can reflect, and also potentially shape, one's sense of identity.

Assessments of time frames are difficult to make because of uncertainties in both psychological sequelae and future events that may or may not be related to the disorder itself. Whether the disease will return, and whether various nonspecific symptoms signal recurrence can remain unclear. The questions of when "the disease ends" depends partly on the definitions of "the disease" and of "the end." Language itself falters in providing accurate and appropriate terms for such often inchoate states that involve uncertain future prognosis. However, these temporal issues (i.e., whether certain phenomena constitute one's state or trait) shape questions of who one is.

I consider myself a "survivor," but hate the term. It indicates that something's done and over; and to me, it's not. I occasionally use that word. I haven't found a better one. When I talk about it, I have varied between saying "I had breast cancer," or "I've had breast cancer," or different things indicating that it's ongoing. If I had to fill out a form, there's a 50/50 chance I would use that term. It is not done and over, because of childbearing decisions, medical things: I have osteopenia, I'm going through perimenopause. My right hip was really troubling me: "Could this be related?" $(B C 7-S x / U n t)$

The presence of familial or genetic risk can resemble "a ticking time bomb," continuing, ever-present. Yet whether one is "sick," "healthy," "a survivor" or none of the above can remain unclear.

\section{Diagnosis as part versus whole of oneself}

Individuals vary not only in what terms they choose in describing themselves, but also to what degree they do so. Genetic risk can constitute a small or large part, but generally not all of one's identity. Individuals then struggle to gauge the actual extent of this identity. The relative amounts, boundaries, and relationships between this versus other parts of the self can vary widely both between people and over time for any one person.

A few individuals felt that the presence of illness or a mutation altered their identities only minimally, if at all. Rarely, individuals saw themselves as being at risk, but felt that this state did not affect their core identity. As one Asian businesswoman said,

I am who I am. I had BC. I beat it. I may get it again. I'll deal with it when I get it again, if I get it again. (BC27 Sx/Inconclusive)

Successful treatment lowered the impact of the illness in her ongoing life. She also appeared driven to succeed in her career, and did not want the disease to interfere.

However, far more commonly, individuals' conditions shaped their views of themselves. Several felt that "genes make me who I am" (BCl) since these individuals would otherwise not exist. Genes are constitutive of the self, and thus, many felt, of their illness as well. At the far extreme, patients with alpha even called themselves "alphas."

Still, many individuals sought to limit or circumscribe the impact of their genetic risk in their lives. This restraint might be easier in individuals who have not had symptoms and/or a mutation.
I don't want to be identified just solely as "I have relatives who had cancer," because that's just placing myself in one situation. There's so much more to a person than just being a cancer survivor, or having relatives who had cancer. $(B C 1-A s x / U n t)$

But individuals varied in how they conceptualized their risk - to whatever degree they felt it existed - in relation to the rest of themselves. Many saw it as merely one part among many.

"It's a piece of who I am. I'm pretty diversified." (BC15Asx/Unt)

Others tried to quantify this portion more precisely. However, the specific degree or size ranged widely. Even HD, although it may seem all-encompassing, can be viewed as simply one part of one's make-up.

I have a genetic link to Huntington's, but it's not my entire being - just one part of me. I have 150 characteristics. This is one of many. So I'm very good about dealing with it like that. I'm obsessional, funny, nice, a hand-washer, a hoarder, a checker (I do a lot of checking) ... ( $(H D 18-S x /+)$

He attempts to quantify HD informally as 1 of 150 features. However, in fact, many of the other characteristics he mentions (e.g., his obsessive-compulsiveness) may be manifestations of it. Others also sought to assess and describe the degrees to which they accepted, embraced, or denied this risk. Some felt that they did not think about their condition "that" often $(B C 20)$, suggesting an objective correlate: the amount of time one spent thinking about it.

I'm able to think about it in a detached way. I don't actually worry about it that much. $(B C 20-A s x / U n t)$

\section{The self as "mutant"?: negative versus positive identities}

Individuals have to decide not only whether to incorporate their condition into their sense of themselves, but also howwith what moral valence (i.e., as positive or negative). They wrestle to gauge whether to view this genetic identity as negative or neutral - and to what degree to do so. A few saw themselves as "mutants," "evolutionary errors," "mistakes," or "freaks of nature." They felt that they had a "bad gene" or "flaw," and struggled to understand it, stumbling at times in seeking appropriate terms. The fact that a mutation can be viewed as tainted can impede construction or embrace of a genetic identity.

There's something wrong with me: I've got this bad gene. I don't know how to explain that. You just feel you're not... I don't want to say you're not perfect, but they might say there's "an identifiable flaw" in your genome. The first thing you think about is: I'm flawed, dirty. I've got this weird disease, this crazy gene. $(A 10-S x /+)$

She searches for metaphors to conceptualize these genes, and their meanings and implications, though remaining uncertain.

There's something wrong with me that's not even physical - its like my body or the blueprints of my body don't work well. The computer that determines the functions of my body, the central processing unit, doesn't work right. 
At any time, something can go wrong. It's like I'm walking with one leg. I don't have the checks and balances most people have. $(B C 13-A s x /+)$

She draws on metaphors from different fields: architecture (blueprints), information technology (computers), medicine (physical handicap), and politics (checks and balances). She and others grope for concrete terms and mechanisms to understand and explain these genetic problems. She continues,

It was explained to me how genes work. There are two: one from your mom, one from your dad. The one from my mom doesn't really do its job. They're supposed to take turns, but one is doing the job all the time. One is shooting blanks or something. I have one chance to get it right. $(B C 13-A s x /+)$

To grasp these mechanisms, she invokes additional metaphors of workplace cooperation ("jobs," and "taking turns," and guns [i.e., firing]).

Many tried to resist potentially negative connotations. One engineer cited the theory of evolution, and said he did not mind being a "mutant" because scientifically, mutations are ubiquitous and thus normal.

I don't call it a "disease," because it would then be worse for me. It's a genetic condition, a mutation. I don't have any qualms with the word mutation. A lot of people do, but I don't. I believe in evolution: We're all mutants. Mutation is the way things change. $(A 10-S x /+)$

He sees his very existence as depending on mutations. Trained in science, he accepts the harsh realities of the disease more than most people, yet at times he also wavers, trying to make sense of it. He struggles to balance the fact that epidemiologically, he is one of the relatively few individuals in the population as a whole who have been diagnosed with a potentially fatal disease for which a mutation has been identified. He faces a more severe genetic problem than most people; although some others are sicker than he. He feels he has also been lucky, having, to date, only relatively mild symptoms.

They claim that everybody has something, but that's just bullshit. One scientist says everybody has four or five flaws that might in the end kill them. But that doesn't really mean that everyone has something. $(A 10-S x /+)$

\section{Factors involved}

As suggested earlier, several factors can shape these viewse.g., scientific education and genetic states themselves, the other ways one defines oneself, and the degrees to which one does so. One African American woman described her other social identities:

Who am I? I'm a grandmother, a woman, a mother, and a human being. I'm pretty intelligent, because I'm always looking for new information. That's basically who I am. $(B C 19-S x / U n t)$

She and several others confronting BC also saw their illness as reflecting social, more than individual medical problems; and they blamed their $\mathrm{BC}$ on environmental factors - e.g., industrial pollution from irresponsible corporations. The mutations for $\mathrm{BC}$, compared to those for $\mathrm{HD}$ or alpha, are less predictive of disease, allowing more lee-way in beliefs about the degree to which genetics (versus other factors) shape oneself, and thus, one's identity.

A mutation can also enforce previous social identities as a member of a group that is commonly affected by a disease. Those with BC, e.g., may attribute it partly to being a woman.

Having this gene makes me feel more female. Women have to deal with special things: having this biological clock, bleeding every month, menopause. It's not a selfpity thing, but an added female thing. $(B C 13-A s x /+)$

Other past traumatic personal experiences can affect these issues as well. Individuals who more strongly and consistently saw themselves negatively as "mutants" appeared to have had particular past psychic trauma (e.g., mental illness). One woman, e.g., who saw herself as "a mutant" due to having $B R C A 1 / 2$, also had a history of depression and suicidality.

When I was 14, I "cut" myself once. Sometimes, I wonder whether I should even have been born. If I weren't here, there would be no difference. (BC13 Asx/+)

The fact that she now had a genetic mutation confirmed her sense that there was something intrinsically "wrong" with her. The extent of disease, and the availability and efficacy of treatment can shape these views, too. Improved treatment and symptoms can help with adaptation to a disease - particularly, a chronic one-altering attitudes.

What helped me change: just living with it. I didn't have this big flashing light or something. $(A 10-S x /+)$

However, even with an effective treatment, ambiguities remain. For example, with alpha, questions arise of whether, despite getting a lung transplant, one continues to "have" alpha.

A lung transplant could change things quite a bit, but I've still got alpha. $(A 8-S x /+)$

The degree to which a patient's symptoms are localized to a particular organ or body part can also mold the impact of the illness on a patient's overall sense of self. Individuals may try to circumscribe the illness to a specific diseased part of their body, thinking of the condition as involving only that part. A woman with alpha who had disease only in her lungs said, "If I didn't have these two lungs, I'd think of myself as healthy." $(A 8-S x /+)$

New as well as previous social settings or groups can shape identity, too. Views of who one is can depend on who one is with at the time. Other people can either support or challenge one's own self-view. At times, one's own and others' views of oneself can coincide.

Whether it is part of my identity now depends on the crowd I'm in. When I'm in an alpha group: I'm one of you. It's part of me, a description of me, like having brown hair, or being this size, or whatever I am. But it's not a total focus. $(A 2-S x /+)$

Disease can constitute "part," but not all of one's identity.

An individual may define him or herself in genetic terms based on temporal factors as well-e.g., only when the topic comes up. 
In terms of who I am, I just say "I had a history of cancer in my family." But it was not there every day-just when we're having the discussion. (BC30 - Asx/Inconclusive)

She framed her identity in familial rather than personal ways: i.e., having had the disease in her family.

Disease communities can further mold identities. Support groups in particular can help patients frame these self-views.

Being involved with this group makes me who I am. $(B C 1-A s x / U n t)$

Yet here, too, over time both community involvements and identities can affect each other.

In the group, we talk about: once you've been diagnosed, you cross a line. We say: once you've had metastatic disease, you cross a different line. Part of my struggle is accepting that - not fighting to get back over to the other side, because that's impossible. $(B C 7-S x / U n t)$

However, seeing oneself as being at risk or having a disease can affect whether and to what degree one even enters a disease community. Similarly, the degrees to which one confronts versus minimizes or denies one's risk can potentially affect one's readiness or resistance to pursue testing or treatment.

\section{Implications}

These issues of identities have implications for coping, and decisions about disclosure, and possibly testing and treatment. For example, individuals' sense of their genetic identity can shape decisions of whether, when, and to what degree to disclose it to others,

Do I tell people that I have a disease? Should I go on job interviews? Do I tell them I'm disabled? Are they hiring a disabled person, or an able? They get some perks for hiring disabled people. $(A 1-S x /+)$

Genetic risk or disease can mold one's private identity, but not necessarily one's wider social identity. Whether one is specifically asked about oneself, and by whom, can affect how one then describes and/or sees oneself.

I am a person at risk, but if someone outside were to say, "tell me about yourself," that's not one of the things that would come to my mind. (BC20-Asx/Unt)

Genetic risk may have affected this asymptomatic, untested patient less than it affects those who have serious symptoms, on-going treatment, and/or mutations with higher penetrance (e.g., HD). Still, these individuals all distinguish between relatively more public versus more private aspects of themselves.

Moreover, outsiders may identify an individual as having a disease, although that individual may resist it. Patients may welcome or resist an identity as "ill" in others' eyes. Entering and exiting the sick role can thus be contested and negotiated.

\section{CONCLUSIONS}

These data highlight how individuals who have, or are at risk for, several different genetic disorders frequently confront, and struggle with, issues of identity, and do so in complex ways. They encounter challenges in trying to incorporate genetic risk information into their on-going lives, and to construct coherent, meaningful senses of themselves. These struggles involve highly subjective interpretations and choices concerning categories related to genetics and disease states more generally. These individuals defined and approached these categories and terms in widely differing ways, based on several factors (e.g., medical history, education, and other sources of identity).

In many regards, genes constitute the self and can shape one's future. However, individuals encounter challenges in gauging and knowing the extent of this predictiveness-e.g., grasping the meanings of "being at risk" or having a mutation while still being asymptomatic. These issues of identity in turn pose challenges for coping - how to overcome a sense of fatalism and hopelessness when confronting possibly deleterious mutations.

In struggling to make sense of their genetic states, individuals generally tried to fit their particular risk or illness into existing socially established categories (e.g., "predisposition," "sick," or "healthy"). They struggled to decide whether these preexisting categories fit them, and if so, how, and to what degree. Generally, they found that these established terms fell short, due to the uniqueness, newness, instability, uncertainty and stigma of genetic risks, causing stress and confusion, and at times impeding health decisions. They also tried to place their genetic state into their previous understandings of, and narratives about, themselves, seeking a sense of narrative coherence.

With regard to previous scholarship on identity formation, Stets and Burke ${ }^{16}$ distinguished between notions of group, role, and personal identity. In this context, although the "sick role" has been described, ${ }^{32}$ as involving certain rights and responsibilities (e.g., to do everything possible to get better), genetics shapes identities at the level of not only broad social roles but also personal individual senses of self. Genetics may involve more subjective, and less socially agreed on self-conceptions. Genetics also poses particular challenges as it involves more inchoate and fine-grained states and categories. For instance, dilemmas arise concerning a mutation that has not yet caused disease. Or, a disease associated with a genetic marker may have been treated, but still recur.

The category of "being at risk" for a genetic disease, but being asymptomatic poses particular problems. With genetic disease, the "objective data" on which these subjective identities are based are themselves highly varied, falling across a spectrum, based on not only symptoms but also ranges of genotypes, phenotypes, and testing states (e.g., being at risk versus testing positive for a mutation). The objective correlates on which subjective identities may be based can be more fluid for genetics than for certain other kinds of diseases. Hence, although Armstrong et al. ${ }^{26}$ suggested that genetic identities involved adjusting to "revealed" aspects of one's self, the data here highlight many other complexities involved - multiple processes and factors, and a range of genotypes and phenotypes that individuals interpret, apply, and incorporate with regard to themselves differently over time. Individuals vary in what aspects of a polymorphism they focus on and how-e.g., as meaning that they are "a mutant" or not. These data underscore the degrees to which the notion of not only "genetic identity" but also "illness identity" are highly complex and multifaceted, with previous authors often using each term to refer to differing phenomena.

Although certain elements of identity arise from biological "givens," these individuals then select and interpret these possible states subjectively, and construct personal meanings for themselves. Their identity appears to be neither wholly constructed (as some postmodern theorists might suggest) nor wholly biological (as a strictly biomedical model might advance), but rather an integrative process between these two approaches. 
Importantly, these data also suggest that how individuals integrate genetic information into their identities can potentially shape coping, and decisions about testing, treatment, and disclosures of risk to family members and others. However, these implications of genetic identities have received little attention heretofore, highlighting needs for future research to explore these areas more fully. It is not clear, e.g., how often individuals see themselves negatively due to having a particular genetic marker, and the degree to which individuals who do so may be less likely to disclose their genetic test results to other at-risk family members.

Between these diseases, similarities and differences emerged, although overall, the similarities in themes and challenges outweighed the differences. Still, many who have a family history of $\mathrm{BC}$, but have neither undergone genetic testing nor displayed symptoms, saw these states as constituting their identities less than did those similarly at risk (without symptoms or mutation) of HD or alpha, since the latter two disorders are more penetrant.

Although some previous scholars have approached these issues from theoretical points of view, this study provides empirical data that addresses many of these issues. For instance, Shiloh $^{25}$ mentions "identity" as a factor involved in patients' understandings of genetic risks, but these scholars tend not to define or describe it - e.g., of what exactly it consists, and what roles exactly it can play. Similarly, Walter and Emery ${ }^{1}$ suggest that individuals develop a "personal sense of vulnerability" concerning risk, but these data highlight how complex these processes can be-shaping, and being shaped by, identity. Individuals choose what aspects of their genetic risk to focus on. Although Zeiler ${ }^{21}$ has proposed several types and dimensions of genetic identity (e.g., qualitative, numerical and personal identity, and identity-over-time), the individuals here raise issues that are both similar and different. The aspects of identity about which these individuals are concerned at times differ from those on which scholars have often focused. For instance, these men and women are concerned about the stigma they might encounter, but not differences between nucleic versus mitochondrial DNA (a scientific distinction).

These individuals underline several other themes concerning identity that have received little attention, but that future research should explore further. For instance, previous theoretical work, while suggesting a multilayered notion of identity, has tended to focus on identity as fixed in time. In contrast, the individuals here illustrate how relationships between genetics and identity can be highly fluid, evolving over time. In addition, these individuals have all learned at one particular point that they are at genetic risk. Hence, their self-knowledge changed, even if their "genetic identity" remained unaltered. That is, they were genetically identical before and after learning of their risk, but their self-perception has metamorphosed. Hence, future scholarship on genetic identity should distinguish, too, between perceived versus actual genetic identity. These data shed light as well on how various multilayers of identity may in fact interrelate and affect each other. Not only can genetics shape personal identity, but personal identity can frame perceptions of genetic identity, as individuals choose which aspects of their genetics to include in their personal concepts of themselves, and how and to what degree. A genetic mutation, causing a disease, can profoundly alter one's identity on multiple layers.

Concerning distinctions made in previous literature between "individualistic" versus "social" conceptions of genetic identity, 22 the individuals here see genetics not as wholly individualistic, but rather as affecting them as well in familial and social contexts, and as having familial, and potentially broader social implications. To a certain degree, these views can thus counter commercial emphasis on "individualized" genetics, although concerns about the latter remain.

Previous scholarship has also questioned, but not answered at what point an identity may change, such that one is no longer oneself-e.g., at what point one becomes a different self. These interviewees grapple with this dilemma, too, posing quandaries of when, if ever, genetic information disrupts previous narratives. These data suggest that the answer may depend, in part, on the strength of previous narratives and the perceived penetrance, predictiveness, and lethality or severity of the newly discovered genetic marker. Frequently, these interviewees did not want to become a different self, but sensed that parts of themselves had nevertheless altered. These individuals suggest, too, a "will to wholeness"- a yearning for coherence-despite these multiple, shifting layers. Future research can address more fully where and what the boundaries are between these diverse strata.

No single definition of identity appears here invariably and universally applicable. Rather, these data suggest that individuals engage in a "process" of seeking to incorporate genetic risk into prior, and now evolving, senses of self. These individuals illustrate the intricacies and nuances of assessing what characteristics indeed constitute one, and how one decides the relative importance and inter-relationships of these, and comes to understand oneself. Tensions surface between different aspects of the definition of the term "identity"- between, e.g., views of oneself by others versus by oneself, characteristics of an individual versus an individual's perception of these characteristics, and degrees of determinism versus free will. Although certain characteristics of an individual may be more objectifiable (e.g., sex, age, or race), others are far less so. Individuals navigate between these alternative and at times competing conceptions, seeking to integrate them. Patients can embody different aspects of the term "identity," at times simultaneously.

These individuals tend not to arrive at clear, definitive answers, but rather, to reflect these tensions. These fluid, complex phenomena will be hard to quantify, but can be elucidated partly through narrative, as suggested here.

These findings shed light, too, on future uses and implications of other genetic tests-including, potentially, markers associated with ancestry and various behavioral traits. Individuals may similarly interpret such genetic information in widely differing ways, relying on their preexisting personal and/or cultural narratives in incorporating this information into their identities. Individuals may vary widely in what aspects of such information they focus on and how and to what degree they do so, reflecting uncertainties of how and to what extent one is in fact shaped by genetic versus other factors. Even decisions of which objective elements to focus on involve important subjective variables.

These data have important implications for professional and public education. Given the relative newness of genetic tests, many physicians still have limited experience or comfort with genetic testing. ${ }^{1}$ Physicians, media, commercial marketers of genetic tests, and others often reify genetics, viewing markers as straightforward, with clear unequivocal meanings. However, these data emphasize the many challenges and ambiguities that persist concerning patients' understandings of genetics. Patients struggle to relate their experiences to commonly used terms such as "healthy," "sick," "diseased," and "disabled"-largely because of ambiguities in prognoses, penetrance, and etiologies. Possessing a polymorphism (i.e., "mutation") can also generate stigma that can impede integrating this genetic information into one's identity. It is vital that health care providers be aware of 
the multifacetedness and vagaries of these issues - of the fluid, protean nature of identity, and patients' struggles to establish satisfactory senses of self, and the ways these phenomena can affect patients' health decisions.

However, these findings pose challenges for providers. Physicians are generally trained to be directive, and to focus on positivistic, objectifiable data. In contrast, notions of identity are, by their very nature, subjective, involving individuals' deeply personal views of themselves and others. Genetic counselors are trained to be more nondirective, yet are in short supply in the United States and elsewhere. At the same time, genetic testing is increasing through both physicians and direct to consumer marketing of tests. Consequently, in upcoming years, more patients will confront and decide to undergo genetic testing, and hence face these issues of identity. Physicians will increasingly need to grapple with the subjective elements, and implications of these tests for individuals. Importantly, providers may benefit from ascertaining, and attending to, how genetic information affects a patient's identity, and how these selfviews can potentially affect health behaviors.

These data have critical implications, too, for future research. For instance, in addition to the areas mentioned earlier, in grappling with these issues, many terms falls short. Social scientists, philosophers, linguists, physicians, genetic counselors, and others should address this problem, to assist patients' understandings of these terms. Future research can investigate in further detail the effects of such words in patients' identity and health decisions - e.g., how physicians and other health care providers perceive and use this vocabulary (e.g., "predisposition," "sick") in communicating with patients. Studies can also probe whether new terms (e.g., incorporating more qualifiers, perhaps along the lines of "healthy alpha") may help patients understand and cope with these quandaries and uncertainties more effectively. Further research can explore more fully, too, how and why patients may alter their identities over time - an area to which social science research in general appears to have given relatively less attention.

These data may have a few potential limitations. For example, we interviewed participants at only one point. But they discussed their experiences over time. Future studies can also investigate these themes further over time.

In sum, these data illustrate several critical issues concerning genetic identity, heightened appreciation of which can potentially enhance clinical care, and education of patients, providers and the broader public, and can help advance research in these areas.

\section{APPENDIX: SAMPLE QUESTIONS FROM SEMISTRUCTURED INTERVIEW}

When did you find out that you had or were at risk for having a genetic disease?

How did you feel about it?

How do you understand that genetic risk? What does it mean for you?

Do you feel you are "disabled," or "sick" or not?

Do you feel genetic information is different than other kinds of health information (e.g., other diagnoses or behaviors such as smoking), and if so, how and why?

Do you see genetic information as more predictive, "powerful" or sensitive? As more part of your identity or self-conception, and if so, how?

\section{ACKNOWLEDGMENTS}

This project was funded through Grant 5-R01-HG002431-01 from the ELSI program of the National Human Genome Research
Institute. I thank Wendy Chung, Karen Marder, Deborah Thorne, Carol Moskowitz, Jennifer Williamson, Edward Eden, Lori Tartell, Ruby Senie, Victor Grann, Carolyn Kumah, and Melissa Conley.

\section{REFERENCES}

1. Walter FM, Emery J. 'Coming down the line'-patients' understanding of their family history of common chronic disease. Ann Fam Med 2005;3:405414.

2. Klitzman R. Being positive: the lives of men and women with HIV. Chicago: Ivan R. Dee, Inc., 1997.

3. Kleinman A. The illness narratives: suffering, healing, \& the human condition. New York: Basic Books, 1988.

4. Riessman CK. Performing identities in illness narrative: masculinity and multiple sclerosis. Qual Res 1988;3:5-33.

5. Mathieson C, Stam H. Renegotiating identity: cancer narratives. Sociol Health Illn 1995;17:283-306.

6. Adams S, Pill R, Jone A. Medication, chronic illness and identity: the perspective of people with asthma. Soc Sci Med 1997;45:198-201.

7. Scharloo M, Kaptein AA, Weinman J, et al. Illness perceptions, coping and functioning in patients with rheumatoid arthritis, chronic obstructive pulmonary disease and psoriasis. $J$ Psychosom Res 1998;44:573-585.

8. Bradley EJ, Calvert E, Pitts MK, Redman CW. Illness identity and the self-regulatory model in recovery from early stage gynaecological cancer. $J$ Health Psychol 2001;6:511-521.

9. Petrie KJ, Weinman J, Sharpe N, Buckley J. Role of patients' view of their illness in predicting return to work and functioning after myocardial infarction: longitudinal study. BMJ 1996;312:1191-1194.

10. Kelly M. Self, identity and radical surgery. Sociol Health Illn 1992;14:390415.

11. McConkie-Rosell A, Spiridgliozzi G, Melvin E, Dawson DV, Lachiewicz AM. Living with genetic risk: effect on adolescent self-concept. Am J Med Genet C 2008;148C:56-69.

12. Brown L, Ed. New shorter Oxford English dictionary. NY: Oxford University Press, 1993.

13. Erikson EH. Identity: youth and crisis. New York: W.W. North \& Company, 1968.

14. Kohlberg L. The psychology of moral development: nature and validity of moral stages. San Francisco: Harper \& Row, 1984.

15. Piaget $P$. The origins of intelligence in children. New York: International Press, 1952.

16. Stets JE, Burke PJ. Identity theory and social identity theory. Soc Psychol $Q$ 2000;63:224-237.

17. Penuel WR, Wertsch JV. Vygotsky and identity formation: a sociocultural approach. Educ Psychol 1995;30:83-92.

18. Foucalt M. Birth of the clinic. New York: Vintage, 1994.

19. Lacan J. The four fundamental concepts of psychoanalysis. New York: Norton, 1998.

20. Zeiler K. Who am I? When do "I" become another? An analytic exploration of identities, sameness and difference, genes and genomes. Health Care Anal 2007; $15: 25-32$.

21. Zeiler K. Symposium on genetics, identify and ethics. New Genet Soc 2009;28:153-156.

22. Widdows H. Between the individual and the community: the impact of genetics on ethical models. New Genet Soc 2009;28:173-188.

23. Nordgren A, Juengst ET. Can genomics tell me who I am? Essentialistic rhetoric in direct-to-consumer DNA testing. New Genet Soc 2009;28:157172.

24. Pierret J. The illness experience: state of knowledge and perspectives for research. Sociol Health Illn 2003;25:4-22.

25. Shiloh S. Illness representations, self-regulation, and genetic counseling: a theoretical review. J Genet Couns 2006;15:325-337.

26. Armstrong D, Michie S, Marteau T. Revealed identity: a study of the process of genetic counseling. SSM 1998;47:1653-1658.

27. Juengst ET. FACE facts: why hum genet will always provoke bioethics. J Law Med Ethics 2004;32:267-275.

28. Elliot C, Brodwin P. Identity and genetic ancestry tracing. BMJ 2002;325: 1469-1471.

29. Geertz C. Interpretation of cultures: selected essays. New York: Basic Books, 1992.

30. Strauss A, Corbin J. Basics of qualitative research grounded theory procedures and techniques. Newbury Park, CA: Sage Publications, 1990.

31. Klitzman R, Thorne D, Williamson J, Chung W, Marder K. Decisionmaking about reproductive choices among individuals at risk for Huntington's disease. J Genet Couns 2007;16:347-362.

32. Parsons T. The social system. London: Routledge and Kegan Paul Ltd., 1992. 